\title{
New genus and species of Oriental Meligethinae with new observations on the genera Cryptarchopria and Kabakovia (Coleoptera: Nitidulidae)
}

\author{
JOSEF JELÍNEK \\ Department of Entomology, National Museum, Golčova 1, CZ-148 00 Praha 4-Kunratice, Czech Republic
}

\begin{abstract}
Key words. Taxonomy, Coleoptera, Nitidulidae, Meligethinae, Horakia kubani, new genus, new species, Kabakovia, Cryptarchopria infima, distribution, biology, palms, Oriental region
\end{abstract}

\begin{abstract}
A new genus and species, Horakia kubani gen. n., sp. n., of Meligethinae from Thailand are described and compared with the closely related genus Cryptarchopria Jelínek. Cryptarchopria infima (Grouvelle) is recorded from the islands Ambon and Seram (Maluku, Indonesia), and its association with flowers of the palm Areca catechu $\mathrm{L}$. is established for the first time. Diagnostic characters of the genus Kabakovia Kirejtshuk, 1979 are discussed, and Kabakovia latipes (Grouvelle, 1908) is recorded from Nepal for the first time.
\end{abstract}

\section{INTRODUCTION}

The subfamily Meligethinae is essentially an Old World group consisting of several hundred small phytophagous Nitidulidae, both the larvae and adults of which develop in flowers of various angiosperms. Species of some predominantly tropical genera, such as Cryptarchopria Jelínek, 1975, Kabakovia Kirejtshuk, 1979, Meligethinus Grouvelle, 1906 and Palmopria Endrödy-Younga, 1978, are associated with flowers of palms and may act as their pollinators (Audisio, 1993; Endrödy-Younga, 1978; Jelínek, 1992; Kirejtshuk \& Kabakov, 1997), thus paralleling the habits of Neotropical Mystropini (Nitidulinae). Fourteen genera of Meligethinae have been recognized, six of them (three exclusively) occurring in the Oriental region.

The genus Cryptarchopria was established by Jelínek (1975) to accommodate a peculiar species from Java, which was originally described as Cryptarcha infima Grouvelle, 1895 because of some superficial similarities with members of the subfamily Cryptarchinae. Further two species from Vietnam were added by Kirejtshuk (1979b, 1989). Recent field observations recorded here suggest that $C$. infima is associated with the flowers of the betel palm Areca catechu L. (Arecales, Arecaceae). Moreover, a new genus representing a sister group of Cryptarchopria, collected by J. Horák and V. Kubáň in Thailand, is described in the present paper. In addition the systematic position of the Oriental genus Kabakovia Kirejtshuk, 1979 is discussed.

\section{DESCRIPTION OF NEW TAXA}

Genus Horakia gen. n.

Type species. Horakia kubani sp. n.

Description. Body small, oval, flatly convex dorsally, densely pubescent (Fig. 11).

Head with temples converging posteriorly. Frons fused with clypeus, extended laterally over insertions of antennae in front of eyes, arcuately emarginate anteriorly, leaving a part of labrum exposed (Fig. 1). Occipital sulcus absent. Antennal furrows broad, converging posteriorly, at outer sides delimited by moderately bulged genae. Paragenae broad, with outer margins partly concealing antennal furrows, short, continued as a fine impunctate and slightly raised edge behind eyes (Fig. 12). Labrum bilobed, mandibles arcuate with pointed tips and one additional tooth behind them. Terminal segments of both maxillary and labial palpi subcylindrical. Mentum subpentagonal (Fig. 2). Antennae 11-segmented, long, with four-segmented club (male), antennomeres II and IV much shorter than the neighbouring ones; scape broad, with basal portion of dorsal surface shallowly concave and bearing short vertical peg articulating with extended side of frons, flagellum without erect setae (Fig. 10).

Anterior margin of pronotum finely bordered, basal not bordered; anterior angles prominent; sides narrowly but distinctly explanate; pubescence recumbent, long and dense. Scutellum semicircular, prescuto-scutellar suture absent. Elytra nearly as long as their combined width, separately rounded apically, transversely strigose, with dense short recumbent hairs.

Prosternum transversely convex, simple, prosternal process flat, broad, shallowly arcuately emarginate apically (Fig. 3). Blunt mediolongitudinal crest of mesosternum opposing prosternal process raised to the level of metasternum, flat in middle, steep laterally; lateral portions of mesosternum concave. Metasternum simple, mesocoxal lines nearly transversely S-shaped, reaching sternopleural sutures near their midlength. Metacoxal lines closely bordering posterior margins of metacoxal cavities, their recurrent lateral portions rectilinear, reaching sides of first abdominal sternum before their midlength. Hypopygium without impressions.

Distances between meso- and metacoxae subequal, twice as broad as distance between procoxae. All femora broadly oval, nearly twice as long as broad, broadly hollowed on dorsal surface for reception of tibiae. Fore tibia with extremely finely crenulate, apparently smooth, recti- 
linear outer margin, outer subapical angle rounded, distinctly finely crenulate (Fig. 4). Meso- and metatibiae flat with simple outer margins, abruptly arcuately dilated inwards at their base, then almost parallel-sided (Figs 5 and 6). Three basal tarsomeres rather narrow, distinctly bilobed. Tarsal claws simple.

Female unknown. Presumably with shorter antennae with 3-segmented club.

Etymology. Dedicated to one of the collectors, Prague coleopterist Jan Horák. Gender: Feminine.

Taxonomic remarks. Most above characters, especially the extended sides of frons, elongate male antennae with four-segmented club and peculiar dorsal articulation of scape, prosternal process dilated behind procoxae and emarginate apically, transversely strigose elytra and hypopygium without arcuate impressions, demonstrate a close relationship of the new genus to Cryptarchopria. Horakia differs from the latter genus especially by some plesiomorphies in the development of antennal furrows and clypeus, thus representing a "missing link" between the highly specialized Cryptarchopria and the rest of Meligethinae. Both genera can be considered as sistergroups, representing a distinct monophyletic clade within the Meligethinae. Some characters, such as foursegmented antennal club in male, shape of prosternal process and transversely strigose elytra, are shared also with the monobasic Oriental genus Kabakovia Kirejtshuk, 1979. Possible relationship of Kabakovia to (Horakia + Cryptarchopria) is discussed below and principal diagnostic characters of the three genera are given in Table 1.

\section{Horakia kubani sp. $\mathrm{n}$.}

(Figs 1-12)

Description. Male. Body small, moderately convex dorsally (Fig. 1). Head and pronotal disc dark brown, elytra and pygidium black-brown, metasternum black, disc of pronotum and pygidium with faint greenish metallic lustre. Sides and large areas at posterior corners of pronotum, narrowly canaliculate sides of elytra, pair of vaguely limited, elongate, anteriorly diverging spots at posterior half of elytral suture and ventral surface brownyellow, dilated sides of frons in front of eyes yellowish translucent, pygidium with narrow yellowish border. Legs yellow, antennae with 2-3 basal segments brown-yellow, becoming gradually darker distad, segments V-XI blackbrown. Pubescence of head and pronotum rather long, thin, recumbent, yellow, on pronotum whirled with local golden reflections resulting in a nebulose pattern; hairs on elytra dense, short, recumbent, dark brown. Length 2.5-2.6 mm, width $1.5 \mathrm{~mm}$.

Head with eyes as wide as the distance between anterior corners of pronotum. Lateral margins of frons in front of eyes almost straight, converging anteriorly, moderately bulged over insertions of antennae. Anterior margin of clypeus broadly and shallowly arcuately emarginate (Fig. 1). Punctures of frons markedly finer than eye facets, simple, separated by 2-3 diameters, becoming closer laterally; spaces between them smooth and shining.

Pronotum widest at basal fourth, almost indistinctly narrowed posteriorly, 1.89-1.91 times wider than medial lenght. Anterior margin truncate, extremely narrowly bordered, anterior angles prominent, acute. Basal margin almost straight, broadly and extremely shallowly emarginate besides subrectangular posterior angles. P/A index 1.59-1.61. Explanate sides in anterior half as broad as sixth antennomere, gradually narrowed posteriorly. Disc moderately convex, smooth and shining, densely punctulate; punctures smaller than those of frons, separated by 0.5-2 diameters, becoming closer (separated by less than one diameter) laterally, with feeble traces of transverse strigosities. Long thin yellow hairs recumbent, diverging radially from several points, thus giving the surface a nebulose appearance resulting from different light refraction. Scutellum semicircular, densely punctulate, with very dense short yellowish hairs.

TABLE 1. Diagnostic characters of the genera Kabakovia Kirejtshuk, Horakia gen. n. and Cryptarchopria Jelínek. A - presumed apomorphy.

\begin{tabular}{|c|c|c|c|}
\hline & Kabakovia & Horakia & Cryptarchopria \\
\hline Frons & $\begin{array}{l}\text { not dilated over insertions of } \\
\text { antennae }\end{array}$ & $\begin{array}{c}\text { dilated over insertions of } \\
\text { antennae (A) }\end{array}$ & $\begin{array}{l}\text { dilated over insertions of } \\
\text { antennae (A) }\end{array}$ \\
\hline Clypeus & narrow, truncate anteriorly & $\begin{array}{l}\text { fused with frons (A), } \\
\text { emarginate anteriorly }\end{array}$ & $\begin{array}{l}\text { fused with frons }(\mathrm{A}) \text {, } \\
\text { subtruncate anteriorly }\end{array}$ \\
\hline Dorsal articulation of scape & not developed & present (A) & present (A) \\
\hline Antennal club in male & four-segmented (A) & four-segmented (A) & four-segmented (A) \\
\hline Outer edge of paragena & short (Fig. 13) & short (Fig. 12) & prolonged to collum (Fig. 15) (A) \\
\hline Antennal furrows on prosternum & absent & absent & present (A) \\
\hline Prosternal process & $\begin{array}{l}\text { dilated behind procoxae, } \\
\text { emarginate apically (A) }\end{array}$ & $\begin{array}{l}\text { dilated behind procoxae, } \\
\text { emarginate apically (A) }\end{array}$ & $\begin{array}{l}\text { dilated behind procoxae, } \\
\text { emarginate apically (A) }\end{array}$ \\
\hline Sides of pronotum & not explanate & explanate (A) & not explanate \\
\hline Elytra & longer than wide & wider than long (A) & wider than long (A) \\
\hline Elytra & transversely strigose $(\mathrm{A})$ & transversely strigose (A) & transversely strigose (A) \\
\hline Tips of female elytra & simultaneously rounded apically & unknown & acuminate apically (A) \\
\hline Hypopygium & $\begin{array}{l}\text { with bisinuate interconnected } \\
\text { impressions (A) }\end{array}$ & without impressions & without impressions \\
\hline
\end{tabular}




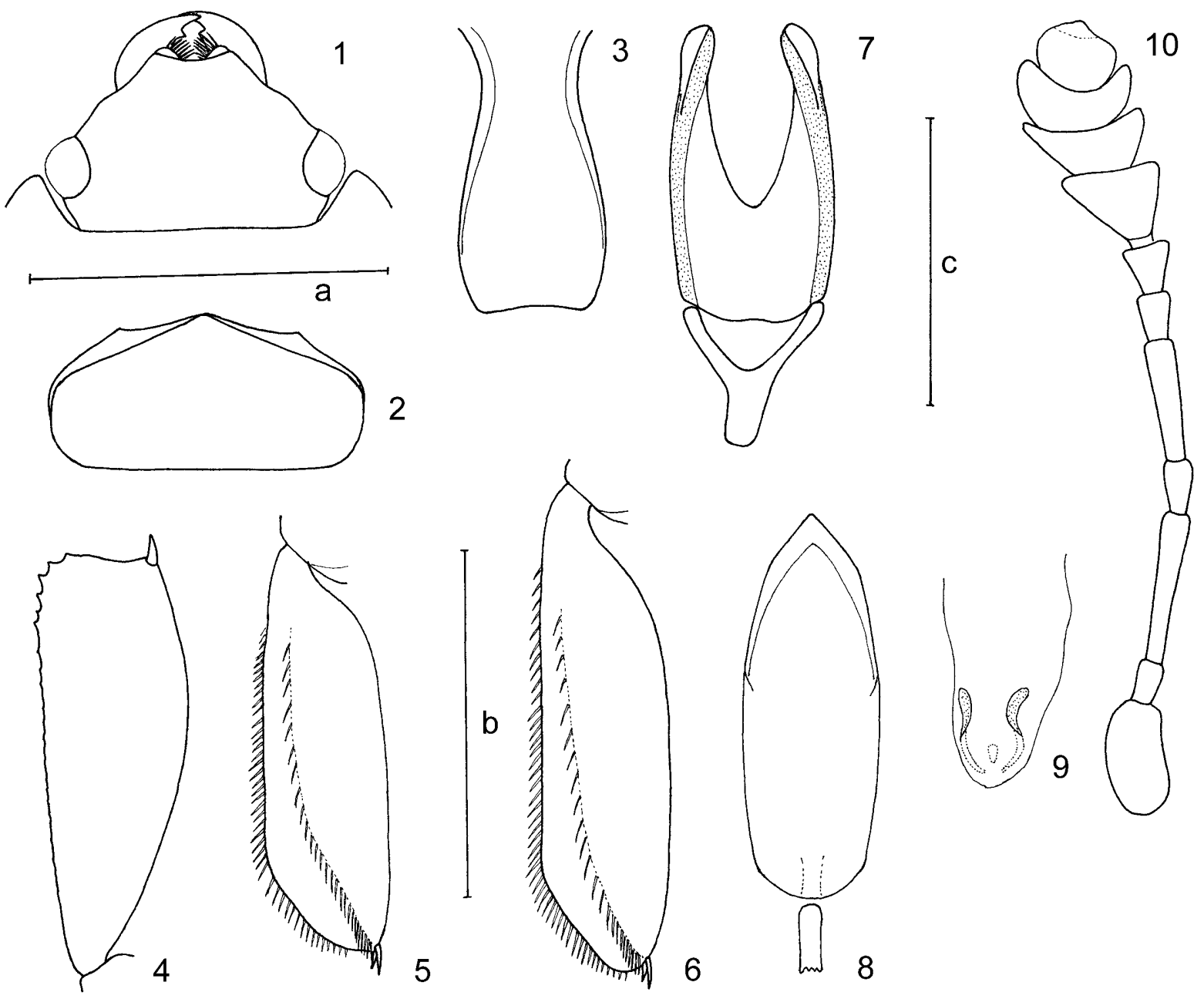

Figs 1-10: Horakia kubani gen. n., sp. n. 1 - dorsal view of head; 2 - mentum; 3 - prosternal process; 4 - anterior tibia; 5 middle tibia; 6 - hind tibia; 7 - tegmen dorsally; 8 - dorsal view of aedeagus; 9 - armature of endophallus; 10 - left male antenna. Scale: a $-1 \mathrm{~mm}$ (Fig. 1); b-0.4 mm (Figs 2-9); c-0.5 mm (Fig. 10).

Elytra as wide as pronotum, widest at basal fourth and there 1.07 times wider than long, broadly separately rounded apically. Lateral margins flatly arcuate, narrowly canaliculate sides by half narower than antennal flagellum. Sutural lines feebly developed along apical third of suture. Humeral angles obtuse, sutural almost rounded, humeral bulges hardly distinct. Surface of elytra transversely strigose with very dense short recumbent silky hairs, as in Cryptarchopria. Pygidium largely exposed, rather flat, rounded apically, densely punctulate, with thin dark recumbent hairs.

Mentum subpentagonal, about 1.8 times wider than long (Fig. 2), with punctures almost equal in size to eye facets and separated by one diameter or less, between them smooth and shining. Postmentum flat in middle, with punctures finer and sparser than those on mentum, between them smooth. Posterior portions of antennal furrows obliquely wrinkled. Prosternum finely densely punctulate, moderately shining, with oblique wrinkles laterally; punctures nearly equal to those of postmentum, but much denser. Hypomera concave, distinctly reticulate, with very obsolete sparse punctures becoming closer at posterior half of lateral margins. Prosternal process widest behind procoxae, bordered laterally, shallowly emarginate apically, punctate like pronotum (Fig. 3). Mesosternum densely microreticulate, with indistinct punctures; its posterior intercoxal margin subtruncate. Metasternum flat in middle, with fine and moderately impressed mediolongitudinal line in posterior two thirds, flatly convex laterally; punctures nearly as fine as those on prosternum, shallow, somewhat aciculate, in middle separated by 1-2 diameters; spaces between them smooth and shining in middle, microreticulate and dull laterally. Axillary spaces microreticulate, impunctate. Punctures of abdominal sterna nearly equal in size to those of metasternum, but markedly closer.

Fore tibia nearly 3.3 times longer than broad, its outer margin rectilinear, almost smooth, inner flatly arcuate; outer subapical angle rounded, finely crenulate, inner with two very short subequal spurs (Fig. 4). Meso- and metatibiae three and four times longer than wide respectively, flat with simple rectilinear margins bearing short dense stout setae, abruptly arcuately dilated inwards in basal third and then nearly parallel-sided (Figs 5 and 6). Three proximal tarsomeres bilobed, those of fore tarsi 

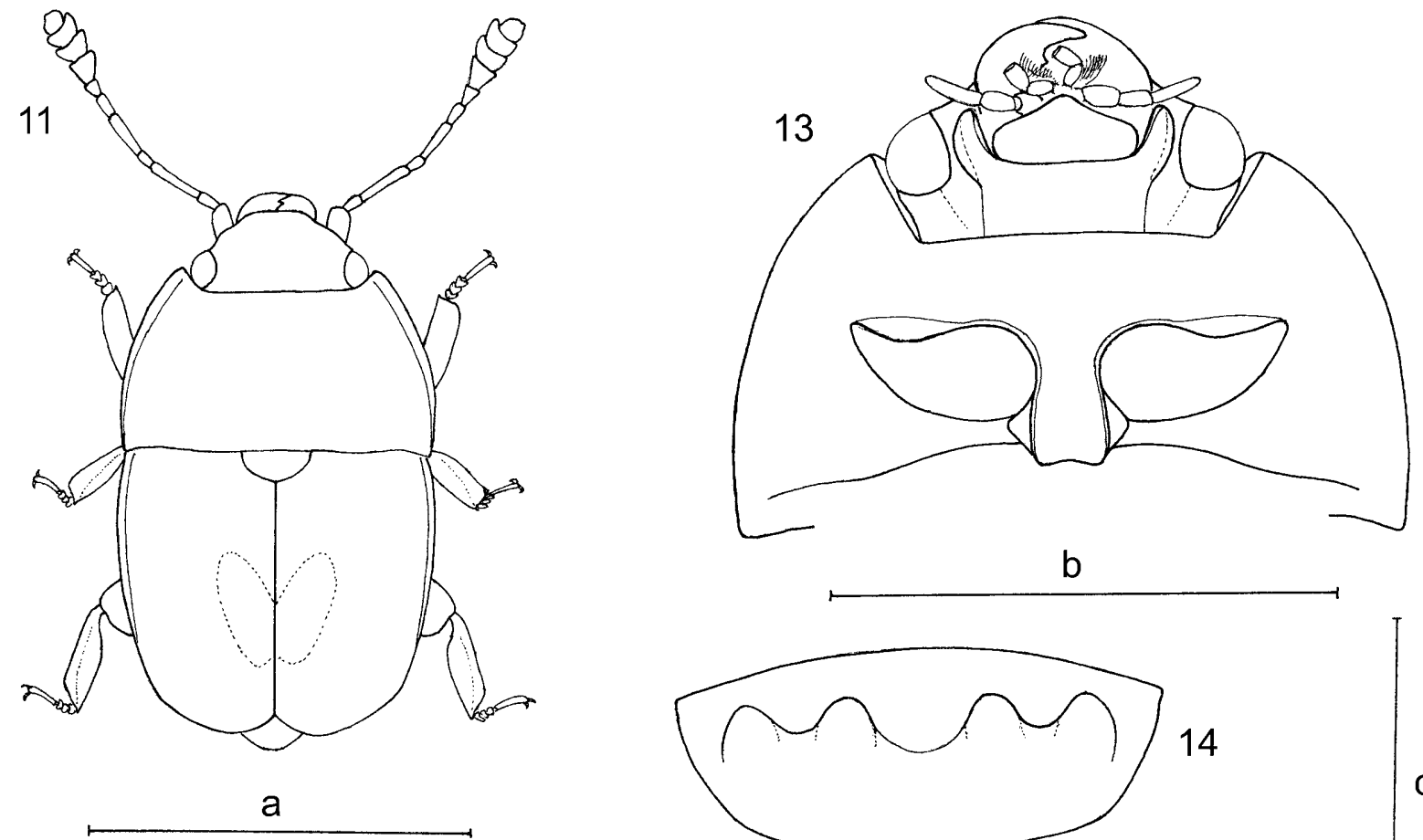

$\mathrm{b}$

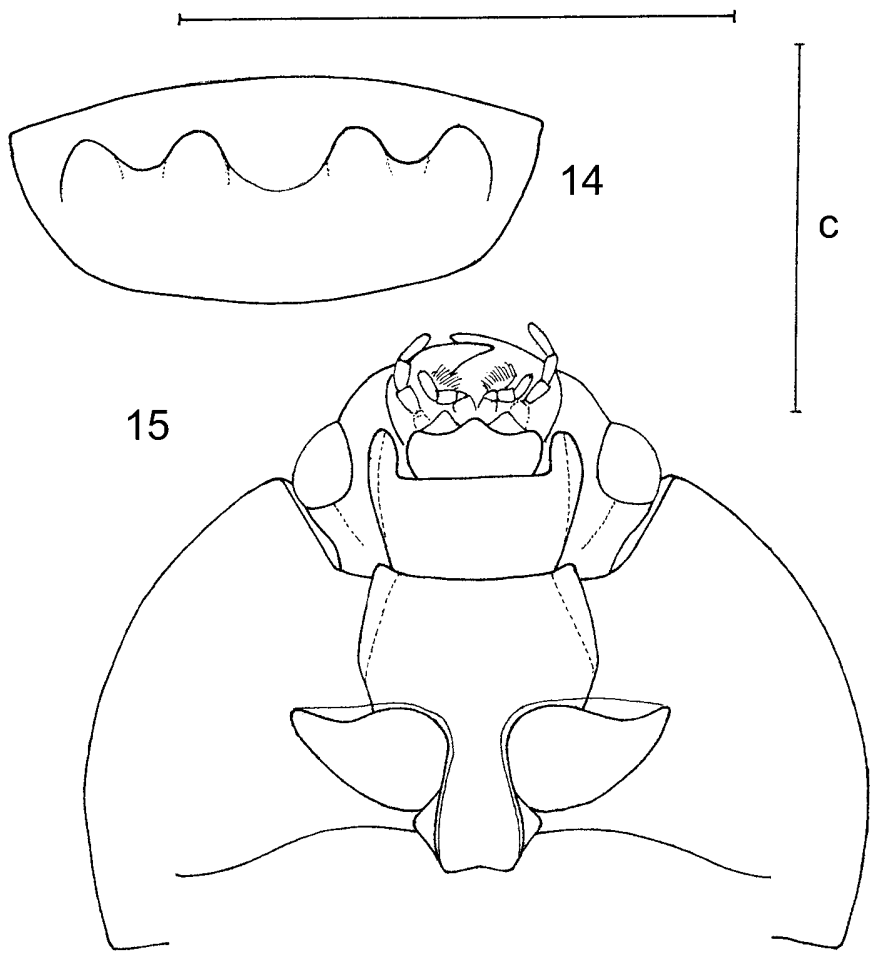

Figs 11-15. 11, 12: Horakia kubani gen. n., sp. n. 11 - habitus; 12 - ventral view of head and prosternum, antennae and legs omitted. 13, 14: Kabakovia latipes (Grouvelle). 13 - ventral view of head and prosternum; 14 - hypopygium. 15 - Cryptarchopria infima (Grouvelle), ventral view of head and prosternum. Scale: a - $1 \mathrm{~mm}$ (Figs 12, 15); b-1 mm (Fig. 13); c - 0.5 mm (Fig. 14).

half width of fore tibia, those of middle and hind tarsi narrower. Tarsal claws simple.

Male genitalia as figured (Figs 7-9). Tegmen with deep $\mathrm{V}$-shaped emargination reaching its midlength, outer portions of rounded tips of lateral lobes not pigmented.

Female unknown. Judging from analogy with Cryptarchopria, sexual dimorphism may occur in the length of antennae, shape of antennal club and shape of elytral apex.

Etymology. Dedicated to the second collector of the species, Vít Kubáň (Brno).

Type material. Holotype, ô, "NW Thai (Mae Hong Son), $19^{\circ} 25^{\prime} \mathrm{N}, 98^{\circ} 20^{\prime} \mathrm{E}$, Soppong, $1,500 \mathrm{~m}$, J. Horák lgt., 7.-12.v.1996". Paratype, 10, "Thai, Mae Hong Son prov., $19^{\circ} 27^{\prime} \mathrm{N}, 98^{\circ} 20^{\prime} \mathrm{E}, 1,500$ m, Soppong, 7.-12.v.1996, Vít Kubán̆ leg." Both in the National Museum, Prague.
Bionomics. Both type specimens were swept from flowers of Castanopsis sp. (Fagaceae). Because the flowers of Castanopsis are attractive to beetles generally (J. Horák, pers. comm.), H. kubani may be a casual visitor to these flowers; this view is supported by the limited number of specimens collected and the absence of females in the sample.

\section{NOTES ON RELATED GENERA}

\section{Genus Cryptarchopria Jelínek, 1975}

Cryptarchopria Jelínek, 1975: 1.

Type species. Cryptarcha infima Grouvelle, 1875 (original designation).

Diagnostic characters of the genus and its relationship to Horakia were discussed above. Three species are 
known at present, occurring in Indonesia [Cryptarchopria infima (Grouvelle, 1895)] and Vietnam (C. kabakovi Kirejtshuk, 1979 and C. ponomarenkoi Kirejtshuk, 1989).

\section{Cryptarchopria infima (Grouvelle, 1895)}

Cryptarcha infima Grouvelle, 1895: 259.

Cryptarchopria infima: Jelínek, 1975: 2.

The type species of the genus Cryptarchopria has been known only from Java. The recently collected material from the Moluccas not only extends the range of the species, but also suggests an association with palm flowers, because the rather extensive material from two different islands was collected exclusively from flowers of the betel palm, Areca catechu L. (S. Bílý and J. Horák, pers. comm.). This observation agrees with that made on the related species C. kabakovi, which was collected from flowers as well as decaying fruits of the palm Arenga pinnata (Wurmb) Merr. in Vietnam (Kirejtshuk \& Kabakov, 1997). C. infina displays considerable variation in colour pattern, ranging from completely brown-yellow specimens to those with almost completely black pronotum and elytra; frequently the disc of pronotum and periscutellar area of elytra are more or less infuscate. Body length $2.5-3.1 \mathrm{~mm}$ in males, $2.1-3.0 \mathrm{~mm}$ in females.

Material examined. Maluku, Ambon Is., Laihatu, Soya, 11.-12.x.1998, S. Bílý lgt., 1ð, 69; Maluku, Seram Is., Air Besar, 6 km E Wahai, 5.xi.1998, S. Bílý 1gt., 14ð, 36 ; dtto, 22.x.1998, J. Horák lgt., 25, 46 ․ All in the National Museum, Prague.

\section{Genus Kabakovia Kirejtshuk, 1979}

Kabakovia Kirejtshuk, 1979a: 356.

Type species. Pria latipes Grouvelle, 1908 (original designation).

The monobasic genus Kabakovia resembles Horakia and Cryptarchopria in having transversely strigose elytra, similar shape of prosternal process and elongate antennae with four-segmented club in male, but differs from both of them by lateral margins of frons not dilated over insertions of antennae, simple basal insertion of antennae, different proportions of flagellomeres (IV and $\mathrm{V}$ of equal length in Kabakovia), and especially in that the hypopygium has a pair of bisinuate impressions arcuately interconnected in the middle (Fig. 14).

\section{Kabakovia latipes (Grouvelle, 1908)}

Pria latipes Grouvelle, 1908: 366.

Kabakovia latipes: Kirejtshuk, 1979a: 358.

Meligethinus latipes: Cooper, 1980: 34.

The only known species of Kabakovia was described as Pria by Grouvelle (1908) and independently transferred to Kabakovia by Kirejtshuk (1979a) and to Meligethinus by Cooper (1980). Because of its peculiar hypopygium, dilated prosternal process and transversely strigose elytra the separation in a distinct genus Kabakovia is justified. The species is known from India (ranging from Kumaon to Nilgiri Hills), Sri Lanka, Vietnam (Cooper, 1980) and Nepal (new record). According to Kirejtshuk \& Kabakov (1997) it is associated with flowers of the palm Phoenix humilis Royle (= hanceana Naud.).
Material examined. Vietnam, Gong-hoi, 200-300 m, 20.iii.1963, Kabakov lgt. / Kabakovia latipes (Grouv.) det. Kirejtshuk A., 1978, 23 , 1 ; Nepal, Janakpur, Dolokha Tamba Koshi, 850-1,100 m, 24.-29.v.1989, C. Holzschuh lgt., 1․ All in the National Museum, Prague.

Comments. Fifteen genera of Meligethinae are recognized including Horakia gen. n. Problems of generic classification of the subfamily and of delimitations of some genera were recently discussed by Audisio (1993). An undoubtely monophyletic clade within the subfamily, characterized by synapomorphic pair of separated arcuate impressions on hypopygium, includes the genera Anthystrix Kirejtshuk, 1981, Cyclogethes Kirejtshuk, 1979, Meligethes Stephens, 1830, Meligethinus Grouvelle, 1906, Metapria Grouvelle, 1909, and Microporum Waterhouse, 1876, and is referred to as the Meligethes-complex below. Among the genera with simple hypopygium, four Afrotropical and Malagassy genera described by Endrödy-Younga (1978), namely Cornutopria, Microporellus, Microporodes and Palmopria, probably also represent a monophyletic group, even though the generic classification of this complex should probably be reexamined and the whole group can be defined so far mostly by symplesiomorphic traits, such as simple puncturation of elytra, antennal club always three-segmented in both sexes, and narrow prosternal process rounded to subtruncate apically. Remaining genera with simple hypopygium share a four- to five-segmented club in males, but while Pria Stephens, 1830 is characterized by narrower oval body, simple frons, basal articulation of scape, narrow prosternal process rounded apically, and regularly punctate elytra, a monophyletic clade (Horakia + Cryptarchopria) is well supported by several synapomorphies, such as broadly oval and flatly convex body, frons dilated over insertions of antennae, secondary dorsal articulation of scape, broad prosternal process arcuately emarginate apically, and transversely strigose elytra. Some of those apomorphies, namely the shape of prosternal process as well as transversely strigose elytra, are shared also by the monobasic Oriental genus Kabakovia. The latter genus possesses a pair of bisinuate interconnected impressions on hypopygium, but this structure differs from that of the Meligethes-complex (see above) and may have developed separately. Kabakovia resembles Horakia and Cryptarchopria also by the somewhat prolonged antennae with four-segmented club in males and is sympatric with them. Similar dimorphism in the shape of antennal club occurs within the Meligethes-complex only in the genus Anthystrix Kirejtshuk, 1981 from South Africa. Antennal club of Anthystrix is said to be four- to six-segmented by Kirejtshuk \& Easton (1988), but the club of Anthystrix longiclava Kirejtshuk \& Easton, 1988, figured in the latter paper (Fig. 1,1), is clearly seven-segmented. However, antennae are never prolonged, prosternal process is narrow, elytra never transversely strigose, and dorsal surface concealed by dense long setae in Anthystrix. Moreover, according to Audisio (pers. comm.), some southern African species with three-segmented male antennal club, described by Kirejtshuk \& Easton (1988) as members of 
Meligethinus, should be also classified as Anthystrix. This would strenghten the notion that the male club with more than three enlarged antennomeres developed independently in Anthystrix. Thus it seems that Kabakovia is a sister-group of (Horakia + Cryptarchopria), as suggested by Kirejtshuk (1979a). The last genus, Prioschema Reitter, 1876 from Liberia, has not been seen by modern authors (type material not found), and judging by some of the characters mentioned in the original description by Reitter (1876), such as bordered basal margin of pronotum, simple tarsi, and each elytron with two longitudinal striae, may not belong to the Meligethinae.

ACKNOWLEDGEMENTS. It is my pleasant duty to express my thanks to S. Bílý (National Museum, Prague), C. Holzschuh (Wien), J. Horák (Prague), A.G. Kirejtshuk (Zoological Institute, Russian Academy of Sciences, St. Petersburg) and V. Kubán (Brno), who provided me with the material, upon which this paper is based, and to V. Zelený (Czech Agricultural University, Prague) for information on the nomenclature of some palm species. Last but not least I am obliged to P. Audisio (Rome) and A.G. Kirejtshuk (St. Petersburg) for their comments on the manuscript, which contributed much to the improvment of the paper. This study was supported by grant No. VZ F02/98 NMPM00001 of the Ministry of Culture of the Czech Republic.

\section{REFERENCES}

Audisio P. 1993: Coleoptera Nitidulidae - Kateretidae. Fauna d'Italia 32. Edizioni Calderini, Bologna, XVI $+971 \mathrm{pp.}$

CoOPER M.C. 1980: Species of the genus Meligethinus Grouvelle (Coleoptera: Nitidulidae). Entomol. Scand. 11: 32-36.

ENDRÖDY-YOUNGA S. 1978: Systematic revision and phylogeny of some Meligethinae genera from the Ethiopian region (Coleoptera: Nitidulidae). Entomol. German. 4: 295-316.
Grouvelle A. 1895: Notes synonymiques et descriptions de Coléoptères clavicornes. Bull. Soc. Entomol. Fr. 1895: 257-259.

Grouvelle A. 1908: Coléoptères de la région indienne. Rhysodidae, Trogositidae, Nitidulidae, Colydiidae, Cucujidae (1. mémoire). Ann. Soc. Entomol. Fr. 77: 315-495.

JELÍNEK J. 1975: New genus of Oriental Meligethinae with notes on supergeneric classification of Nitidulidae (Coleoptera, Nitidulidae). Annot. Zool. Bot. (Bratislava) No. 102: 1-9.

JEĹ́NEK J. 1992: Nitidulidae (Coleoptera) associated with flowers of oil palm, Elaeis guineensis (Arecales, Arecaceae), in Rwanda. Acta Entomol. Bohemoslov. 89: 409-428.

Kirejtshur A.G. 1979a: Two new genera and new species of the subfam. Meligethinae (Coleoptera, Nitidulidae) from Vietnam. Entomol. Obozr. 58: 355-368 (in Russian, English abstr.).

KIREJTSHUK A.G. 1979b: New species of the Cryptarchopria Jelínek genus (Coleoptera; Nitidulidae; Meligethinae) from Vietnam and its variability. Dokl. Akad. Nauk Ukrainskoi SSR (B) 1979: 383-387 (in Russian, English abstr.).

KrReJTshur A.G. 1989: New taxa of the Nitidulidae (Coleoptera) of the East Hemisphaera (Part III). In Kirejtshuk A.G. (ed.): Problems of systematics of Coleoptera. Trudy Zool. Inst. (Leningrad) 208: 64-89 (in Russian).

KrRetTShur A.G. \& Easton A.M. 1988: Revision of the genus Anthystrix Kirejtshuk and new species of the subfamily Meligethinae (Coleoptera, Nitidulidae) from South Africa. Trudy Vsesoyuz. Entomol. Obshch. 70: 41-55 (in Russian).

KIREJTSHUK A.G. \& KaBAKOV O.N. 1997: Observations on the nitidulid beetles (Coleoptera, Nitidulidae) collected by O.N. Kabakov in Vietnam and Laos. Izv. Kharkov. Entomol. Obshch. 5(2): 13-22 (in Russian).

RertTeR E. 1876: Neue Clavicornien, beschrieben von Edm. Reitter. Stett. Entomol. Ztg. 37: 363-368.

Received February 7, 2000; accepted April 14, 2000 